\title{
Observation time and spontaneous resolution of primary phimosis in children
}

\section{Tempo de observação e resolução espontânea de fimose primária em crianças}

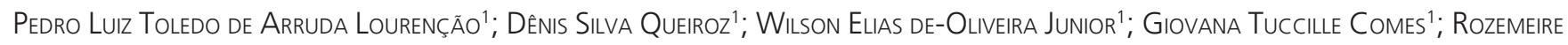

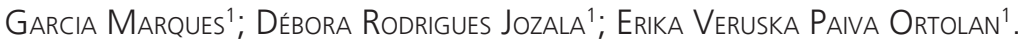

\begin{abstract}
A B S T R A C T
Objective: to investigate spontaneous resolution rate of a series of patients with physiologic phimosis in relation to observation time and presence of symptoms. Methods: retrospective and longitudinal follow-up study of patients with physiologic phimosis, that did not apply topic treatment. These patients were invited for a new visit for reevaluation, or recent data were obtained by chart analysis. Spontaneous resolution rate was determined and statistically compared to age, presence of symptoms at first medical visit and time until reevaluation. Results: seventy one patients were included. Medium time of observation from first visit to reevaluation was 37.4 months. There was spontaneous resolution of phimosis in 32 (45\%) patients. Children with spontaneous resolution were younger at initial diagnosis and were observed during a longer period of time. Most asymptomatic patients at first visit presented spontaneous resolution. However, it was not possible to stablish a significant relationship between presence of symptoms and evolution of physiologic phimosis. Conclusions: time of observation was the main determinant of spontaneous resolution of patients with physiologic phimosis, reinforcing the current more conservative approach regarding circumcision of those patients.
\end{abstract}

Keywords: Phimosis. Circumcision, Male. Child.

\section{INTRODUCTION}

D himosis is a clinical condition where prepuce does not allow the exposure of glans ${ }^{1,2}$. Primary physiologic phimosis is considered when prepuce is normal (also histologically) but does not allow glans exposure and usually spontaneously resolves until adolescen$\mathrm{ce}^{3,4}$. On the other hand, secondary or pathologic phimosis is defined as the absence of glans exposure due to the presence of a fibrous ring at prepuce, due to repeated balanoposthitis, ammoniacal dermatitis, or sclerous-atrophic liquen of unknown origin ${ }^{5-8}$.

Up to $96 \%$ of boys are born with phimosis, being one of the most common diagnosis in Pediatrics ${ }^{9}$. However, although with high prevalence and, usually, with a benign evolution, treatment is controversial ${ }^{10}$. Circumcision is the surgical removal of prepuce and is one of the most ancient described surgical procedures and one of the most performed nowadays ${ }^{11}$. In the last years, medical indication of circumcision is being limited, due to encouraging results of the use of topic corticoids, and natural evolution with spontaneous resolution of patients with physiologic phimosis ${ }^{12-14}$. At the present, it is being advocated to limit and postpone surgical procedure, reserving it to patients with recurrent balanoposthitis, recurrent urinary infections, to adolescents that cannot completely expose their glans and to patients with pathologic phimosis. However, one every six boys in the World will be submitted to circumcision ${ }^{4}$. Aside from ethnic and religious factors (responsible for neonatal circumcision in some cultures), familial pressure is responsible for a large number of surgeries. In clinical practice, in many occasions it is very hard to convince family of conservative expectant treatment. Parents hardly believe that phimosis will spontaneously resolve and desire to anticipate surgery, even of asymptomatic patients ${ }^{17}$.

Therefore, it is very important to perform studies to verify the natural evolution of physiologic

1 - Botucatu School of Medicine (UNESP), Pediatric Surgery Division, Department of Surgery and Orthopedics, Botucatu, São Paulo, Brazil. 
phimosis and spontaneous resolution. We decided to investigate spontaneous resolution rate of a series of patients with physiologic phimosis, and to verify which factors influence this evolution.

\section{METHODS}

Retrospective study, with longitudinal observational follow-up, of patients up to 15 years old, attended at Pediatric Surgery Ambulatory at Clinical Hospital of Botucatu Medical School - UNESP, from 2006 to 2013, with diagnosis of phimosis; patients were in a waiting list to perform elective circumcision. Until 2013, we performed circumcision in all patients older than two years old, with physiologic phimosis, that were not using diapers.

Former data were obtained by chart analysis; age at first medical appointment (phimosis diagnosis), symptoms (micturition difficulties ("ballooning"), balanoposthitis, paraphimosis, urinary tract infections) were recorded, as well as physical exam observations and use (or not) of topical corticosteroids. Patients were contacted by phone to attend a new consultation for reevaluation. In that moment, it was determined the time between first consultation and reevaluation, age, presence of symptoms and physical exam findings, previous use of topic treatment, and phimosis spontaneous resolution or not. For patients that could not be contacted by phone, or that did not attend consultation, reevaluation data were obtained by analysis of medical charts at the most recent ambulatory visit, if it occurred in the last six months. For patients already submitted to circumcision, reevaluation data were collected at the medical evaluation at surgery that was considered the reevaluation date.

In all moments of the study, phimosis diagnosis was made by non- retractile prepuces, represented by types 3, 4 and 5 of Kikiros et al. ${ }^{12}$ scale of retractility of prepuce. Prepuces type 0, 1 and 2 were considered normal. In the study it was included all patients at waiting list with physiologic phimosis. Patients with secondary phimosis that were submitted to any topic treatment and those who did not attend reevaluation medical appointments or without recent information (last six months) were excluded.
Descriptive statistical analysis was made by determination of frequencies and percentages of categorized variables and medium, median and standard deviations of continuous variables. Comparison of patients with spontaneous resolution or not, related to age at diagnosis, age at reevaluation and time from first medical appointment to reevaluation, was made by variance analysis (ANOVA), followed by Tukey test. To verify the association between spontaneous resolution rate of phimosis and age groups, interval between first and reevaluation medical appointment, and presence of symptoms at first visit, it was performed Chi-square test. Comparison between symptoms at different moments of evaluation was made by Proportion Analysis Test. Comparison between median time until reevaluation of operated patients and with spontaneous resolution was made by Student $t$ test. Significance level was $5 \%$ and it was used the SAS program for Windows version 9.2.

This study was approved by the Ethical Committee in Research of Botucatu Medical School (CAAE $n^{\circ}$ 27102714.7.0000.5411). All patients' parents and/ or guardians that attended medical visits signed a free consent form, and patients older than 11 years old also signed the consent form.

\section{RESULTS}

Ninety nine children were followed from 2006 to 2013 and were included in the waiting list for circumcision. Twenty eight patients were excluded due to topic treatment, pathological phimosis or absence at the reevaluation medical appointment or lack of recent information regarding phimosis. In the end, 71 patients were included in the study.

Medium time of observation (between first and reevaluation medical appointments) was 37.4 months. Spontaneous resolution of physiologic phimosis was observed in 32 patients (45\%). Among those 39 without resolution, 32 ( $82 \%$ ) had already been submitted to circumcision. For these patients, data of surgery was considered reevaluation data. Comparison between patients with and without spontaneous resolution, related to median age at diagnosis and at reevaluation, and medium time between both moments of evaluation is shown in table 1. When those 32 circumcised patients were specifically 
analyzed, medium time of observation was significantly lower than of patients with spontaneous resolution (26.3 months versus 48.5 months; $p=0.002$, t-Student test). On the other hand, children without spontaneous resolution were significantly older than those with spontaneous resolution (60.2x44.2 months; $p=0.004$, ANOVA, Tukey).

Table 1. Comparison of ages of patients at first and reevaluation medi$\mathrm{cal}$ appointments and time between these two moments, in relation to phimosis evolution.

\begin{tabular}{|c|c|c|c|}
\hline & $\begin{array}{l}\text { Spontaneous } \\
\text { resolution } \\
(n=32) \\
\text { Medium } \\
\text { ( } \pm \text { standard } \\
\text { deviation) }\end{array}$ & $\begin{array}{l}\text { Without } \\
\text { spontaneous } \\
\text { resolution } \\
(\mathrm{n}=35) \\
\text { Medium } \\
\text { ( } \pm \text { standard } \\
\text { deviation) }\end{array}$ & $p^{*}$ \\
\hline $\begin{array}{l}\text { Age at first } \\
\text { medical } \\
\text { appointment } \\
\text { (months) }\end{array}$ & $44.2( \pm 30.3)$ & $60.3( \pm 35.4)$ & 0.04 \\
\hline $\begin{array}{l}\text { Age at } \\
\text { reevaluation } \\
\text { (months) }\end{array}$ & $92.7( \pm 37.9)$ & $88.6( \pm 42.8)$ & 0.67 \\
\hline $\begin{array}{l}\text { Time between } \\
\text { first medical } \\
\text { appointment } \\
\text { and reevaluation } \\
\text { (months) }\end{array}$ & $48.5( \pm 30.6)$ & $28.2( \pm 25.5)$ & 0.003 \\
\hline
\end{tabular}

Stratification in intervals of time of observation, between first and reevaluation medical appointments, in relation to spontaneous resolution of phimosis, is shown in figure 1. Most patients with interval of observation lower than five years did not present spontaneous resolution (32×19), while most with at least five years of interval $(13 \times 7)$ showed spontaneous resolution ( $p=0.03$; Chi-square test). There were no statistical significant differences between stratified spontaneous resolution rates of different age groups (lower than 5 years, 5 to 7 years, 7 to 10 years, older than 10 years) at clinical reevaluation ( $p=0.91$; Chi-square test).

Clinical symptoms present in both moments of evaluation are resumed at table 2. Most patients were asymptomatic in both moments, and the most common symptom in both was micturition alteration ("ballooning"). Proportion of asymptomatic patients was significantly higher at reevaluation than at first medical appointment $(p=0.01)$. There were three times more patients that already had paraphimosis at reevaluation.

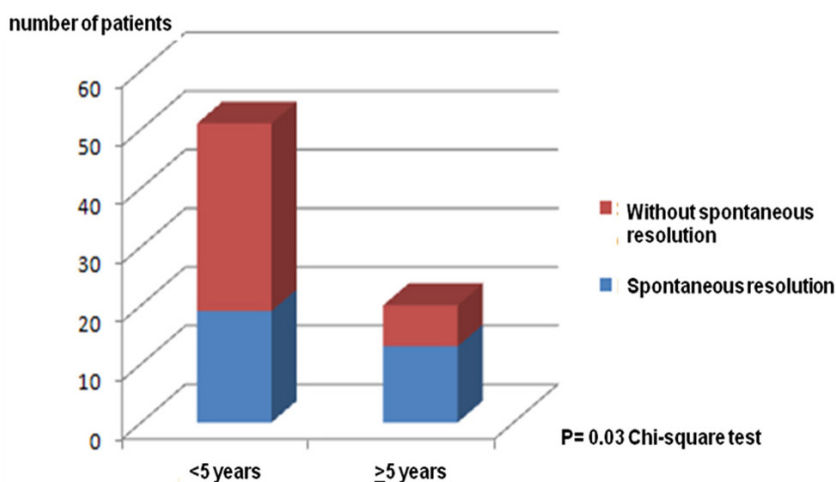

Figure 1. Spontaneous resolutión $x$ observation time.

Spontaneous resolution of phimosis in relation to presence of symptoms at first medical appointment was also investigated. Among 34 patients with symptoms at first medical appointment, 13 (38.2\%) showed spontaneous resolution and 37 that were asymptomatic at first medical appointment, 19 (51\%) presented spontaneous resolution, with higher rate of spontaneous resolution of patients initially asymptomatic $(p=0.2672$; Chi-square test).

Table 2. Clinical symptoms at first and reevaluation medical appointments.

\begin{tabular}{|c|c|c|c|}
\hline Symptoms & $\begin{array}{l}\text { First medical } \\
\text { appointment }\end{array}$ & Reevaluation & $\begin{array}{l}\text { Difference of } \\
\text { proportions* }\end{array}$ \\
\hline $\begin{array}{l}\text { Micturition } \\
\text { "ballooning" }\end{array}$ & $32.4 \%(23 / 71)$ & $\begin{array}{l}19.7 \% \\
(14 / 71)\end{array}$ & $\begin{array}{c}z=1.720645 ; \\
p=0.08\end{array}$ \\
\hline $\begin{array}{l}\text { Previous urinary } \\
\text { tract infection }\end{array}$ & $15.5 \%(11 / 71)$ & $\begin{array}{c}9.86 \% \\
(7 / 71)\end{array}$ & $\begin{array}{c}z=1.008921 ; \\
p=0.3283\end{array}$ \\
\hline $\begin{array}{c}\text { Previous } \\
\text { episode of } \\
\text { paraphimosis }\end{array}$ & $1.4 \% \quad(1 / 71)$ & $\begin{array}{l}4.2 \% \\
(3 / 71)\end{array}$ & $\begin{array}{c}z=-1.014389 ; \\
p=0.3697\end{array}$ \\
\hline $\begin{array}{c}\text { Previous } \\
\text { episode of } \\
\text { balanoposthitis }\end{array}$ & $23.9 \%(17 / 71)$ & $\begin{array}{l}11.2 \% \\
(8 / 71)\end{array}$ & $\begin{array}{c}z=1.983005 \\
p=0.0474\end{array}$ \\
\hline Asymptomatic & $52.1 \%(37 / 71)$ & $\begin{array}{l}73.2 \% \\
(52 / 71)\end{array}$ & $\begin{array}{c}z=-2.60257 \\
p=0.01\end{array}$ \\
\hline
\end{tabular}

* Proportion Difference Test ( $\mathrm{Z}$ test). 


\section{DISCUSSION}

Although circumcision is one of the most ancient procedures in history of surgical interventions, and one of the most commonly in childhood, its indication is still very controversial2,18. Surgical intervention is not necessary to correct phimosis of all children with non-retractile prepuce ${ }^{16}$. This resolution will occur physiologically in most of these children ${ }^{19}$. Gairdner ${ }^{20}$ observed resolution in $90 \%$ of patients until three years old and in $99 \%$ until 17 years old. Kaplan ${ }^{21}$ showed that only $4 \%$ of children had a totally retractile prepuce at birth, and that $50 \%$ presented it completely closed without visualization of urethral orifice. On the other hand, at six months of age, it was observed retractile prepuce in $20 \%$ of boys. Similar results were also obtained by Kayaba et al. ${ }^{22}$ among 603 Japanese boys. Incidence of totally retractile foreskin gradually increased from $0 \%$ at six months old to $62.9 \%$ in age group of 11 to 15 years old.

Routine circumcision for all boys, with different ages, although performed in many centers, is not considered a necessary treatment by most guidelines, although some evidences show potential benefits like diminishing risk of sexually transmitted diseases, urinary infections prophylaxis and cancer of penis ${ }^{17,18}$. Absolute indications for circumcision include xerotic balanitis and recurrent balanoposthitis, that affect approximately $2 \%$ of children ${ }^{4,14,16}$. Balanoprepucial adhesions, esmegma cysts, micturition "ballooning", and non-retractile prepuce are physiologic conditions, and parents must be tranquilized, without the need of specialist evaluation ${ }^{4}$. Adolescents that did not present spontaneous resolution also have surgical indication ${ }^{16}$. Relative indications include recurrent urinary infections, long foreskin and resolved episodes of paraphimosis ${ }^{4,23}$. Also, recent results with topic treatment with corticosteroids are promising and limit routine circumcision ${ }^{12,13,19}$.

Our study included a series of children with physiologic phimosis, initially evaluated between 2006 and 2013, observed for a medium period of 37.4 months. There was spontaneous resolution in $45 \%$ of patients. Children with spontaneous resolution were younger at initial diagnosis $(44.2 \times 60.3$ months; $p=0.04)$ and were followed-up for longer period of time $(48.5 \times 28.2$ months; $p=0.003)$. Although medium age at first medical appointment was higher for those without spontaneous resolution, spontaneous resolution rates showed little variation among different age groups $(p=0.91)$, showing that this physiologic evolution may occur in different age groups, from five years until adolescence, with more than ten years. It was not possible to stablish a "cut-off" age for spontaneous resolution.

Most children followed-up for a minimum of five years showed spontaneous resolution $(p=0.03)$. On the other hand, in our series, most patients were followed-up for less than five years. Among 39 children without spontaneous resolution, 32 had already been submitted to circumcision. Medium time of observation of those patients was lower than of patients with spontaneous resolution ( $26.3 \times 48.5$ months; $p=0.002$ ). Among those 32 operated, 19 (59.3\%) had initial symptoms of balanoposthitis, paraphimosis or urinary infections, that justified surgery ${ }^{4}$. The 13 other patients $(40.7 \%)$ remained asymptomatic, but were operated after a short period of time, for they were the first in the waiting list. It is our belief that many of these patients did not present spontaneous resolution due to the fact of insufficient time for its occurrence.

Most children were asymptomatic, at first and at reevaluation medical appointments. Also, among asymptomatic children, the most common clinical complaint in both moments of evaluation was micturition "ballooning", a very common symptom that provokes anxiety of parents, but that must be considered physiologic and without absolute indication for surgery ${ }^{4}$. It is important to stress the significant higher number of patients with balanoposthitis at first consultation than at reevaluation. During initial visit, orientations about local hygiene and care may explain diminishing of these symptoms during follow-up. All symptoms were more commonly present at first consultation than at reevaluation, except paraphimosis episodes. This may be explained by the fact that this complication increases with time, being more common in older children ${ }^{4,23}$.

Although most asymptomatic patients presented spontaneous resolution, it was not possible to stablish a significant relationship between presence of symptoms and physiologic phimosis evolution $(p=0.2672)$. This is highlighted by the fact that 13 of 
34 symptomatic patients at first medical appointment presented spontaneous resolution.

In our series of patients, the main factor that determined spontaneous resolution of physiologic phimosis was the time of observation, preferably with more than five years intervals. Presence of symptoms such as balanoposthitis, paraphimosis episodes or urinary tract infections may influence evolution, determining an earlier surgical intervention. In spite of all controversial data about medical indication of circumcision, and the potential benefits of routine neonatal circumcision, our data reinforce current tendency for more conservative approach of circumcision indication in patients with physiologic phimosis. More important is "enough time" for spontaneous resolution. For that, it is important to explain the parents the reasons for this conservative approach and the real chance of spontaneous resolutions. Risks related to surgical and anesthetic procedure, health care costs, high rate of spontaneous resolution of physiologic phimosis and high rate of success of topic treatment, are important to limit indication of routine circumcision. At present, in our service, we limit indications of postectomy to secondary phimosis, for those with balanoposthitis episodes, or urinary tract infections, and for adolescents with physiologic phimosis without result with topic treatment.

\title{
R E S U M O
}

\begin{abstract}
Objetivo: investigar a taxa de resolução espontânea de uma série de pacientes com diagnóstico de fimose fisiológica e sua relação com o tempo de observação e com a presença de sintomas. Métodos: estudo retrospectivo e de seguimento longitudinal e observacional de pacientes em acompanhamento por fimose fisiológica, que não haviam realizado tratamento tópico. Estes pacientes foram convocados para uma consulta médica de reavaliação ou tiveram dados recentes obtidos a partir da análise dos prontuários. A taxa de resolução espontânea foi determinada e comparada estatisticamente de acordo com a idade, com a presença de sintomas no momento da primeira consulta e com o tempo transcorrido entre a primeira consulta e a reavaliação. Resultados: setenta e um pacientes foram incluídos no estudo. O tempo médio de observação, entre a primeira consulta e a reavaliação foi de 37,4 meses. Houve resolução espontânea da fimose em 32 (45\%) pacientes. As crianças que apresentaram resolução espontânea eram mais jovens no momento do diagnóstico inicial e foram observadas por um maior intervalo de tempo. A maior parte dos pacientes assintomáticos na primeira consulta apresentou resolução espontânea. No entanto, não foi possível estabelecer uma relação significativa entre a presença de sintomas e a evolução da fimose fisiológica. Conclusões: o tempo de observação foi o maior determinante para a resolução espontânea de pacientes com fimose fisiológica, o que reforça a tendência atual mais conservadora em relação às indicações de circuncisão para estes pacientes.
\end{abstract}

Descritores: Fimose. Circuncisão Masculina. Criança.

\section{REFERENCES}

1. Braz A. Fimose. Curso de patologias cirúrgicas do pênis e escroto na criança. Pediatr Atual. 1998; 11:54-66.

2. Hodges FM. Phimosis in antiquity. World J Urol. 1999;17(3):133-6.

3. Ashfield JE, Nickel KR, Siemens DR, MacNeily $A E$, Nickel JC. Treatment of phimosis with topical steroids in 194 children. J Urol. 2003;169(3):1106-8.

4. Malone P, Steinbrecher $\mathrm{H}$. Medical aspects of male circumcision. BMJ. 2007; 335(7631):1206-90.

5. Spilsbury K, Semmens JB, Wisniewski ZS, Holman $C D$. Circumcision for phimosis and other medical indications in Western Australian boys. Med J Aust. 2003; 178(4):155-8.

6. Higgins TT, Williams DI, Ellison Nash DF. The urology of childhood. London: Butterworths; 1951.

7. Robarts FH. Penis and prepuce. In: Mason Brown JJ, editor. Surgery of childhood. London: Edward Arnold; 1962. p. 1159-81.

8. Catterall RD, Oates JK. Treatment of balanitis xerotica obliterans with hydrocortisone injections. $\mathrm{Br}$ J Vener Dis. 1962;38:75-7.

9. Shahid SK. Phimosis in children. ISRN Urol. 2012; 2012:707329.

10. Ng WT, Fan N, Wong CK, Leung SL, Yuen KS, Sze YS, et al. Treatment of childhood phimosis with a moderately potent topical steroid. ANZ I Surg. 2001; 71(9):541-3.

11. Marzaro M, Carmignola G, Zoppellaro F, Schiavon $G$, Ferro M, Fusaro $F$, et al. [Phimosis: when does it require surgical intervention?]. Minerva Pediatr. 1997;49(6):245-8. Italian. 
12. Kikiros CS, Beasley SW, Woodward AA. The response of phimosis to local steroid application. Ped Surg Int. 1993;8(4):329-32.

13. Pileggi $F$ de $O$, Vicente $Y A$. Phimotic ring topical corticoid cream $(0.1 \%$ mometasone furoate) treatment in children. J Pediatr Surg. 2007;42(10):1749-52.

14. Tekgül S, Riedmiller $H$, Gerharz E, Hoebeke $P$, Kocvara R, Nijman R, et al; Guidelines on Paediatric Urology. European Society for Paediatric Urology: Nice (FR); 2008.

15. Fergusson DM, Lawton JM, Shannon FT. Neonatal circumcision and penile problems: an 8-year longitudinal study. Pediatrics. 1988;81(4):537-41.

16. Koff WJ, Damião R, Correrette FB; Sociedade Brasileira de Urologia. Reuniões de consensos e diretrizes. Sociedade Brasileira de Urologia - SBU. Rio de Janeiro: SBU; 2005.

17. Morris BJ, Waskett JH, Banerjee J, Wamai RG, Tobian $A A$, Gray $R H$, et al. A 'snip' in time: what is the best age to circumcise? BMC Pediatr. 2012;12:20.

18. Simpson E, Carstensen J, Murphy P. Neonatal circumcision: new recommendations \& implications for practice. Mo Med. 2014;111(3):222-30.
19. Sneppen I, Thorup J. Foreskin morbidity in uncircumcised males. Pediatrics. 2016;137(5): pii: e20154340.

20. Gairdner D. The fate of foreskein: a study of circumcision. Br Med J. 1949; 2(4642):1433-7.

21. Kaplan GW. Complications of circumcision. Urol Clin North Am. 1983;10(3): 543-9.

22. Kayaba H, Tamura H, Kitajima S, Fujiwara $Y$, Kato $T$, Kato T. Analysis of shape and retractability of the prepuce in 603 Japanese boys. J Urol. 1996; 156(5):1813-5.

23. Pohlman GD, Phillips JM, Wilcox DT. Simple method of paraphimosis reduction revisited: point of technique and review of the literature. J Pediatr Urol. 2013;9(1):104-7.

Received in: 15/05/2017

Accepted for publication: 22/06/2017

Conflict of interest: none.

Source of funding: none.

\section{Mailing address:}

Pedro Luiz Toledo de Arruda Lourenção

E-mail: plourencao@gmail.com / lourencao@fmb.unesp.br 